\title{
Can A Nursing Intervention Improve the Sleep Pattern Disorders in Patients Undergoing Hemodialysis in Morning and Afternoon Shifts?
}

\author{
Nadia Mohamed Taha ${ }^{* 1}$, Zeinab Hussain Ali $^{2}$ \\ ${ }^{1}$ Medical Surgical Nursing, Faculty of Nursing, University of Zagazig, Zagazig, Egypt \\ ${ }^{2}$ Adult Health Nursing, Faculty of Nursing, of Helwan, Helwan, Egypt
}

Corresponding author: Nadia Mohamed Taha, Assistant professor in Medical Surgical Nursing, Faculty of Nursing, Zagazig University. Zagazig, city 44511, Egypt, Tel: 0020224330793; E-mail: dr_nadya_mohamed@yahoo.com

Received date: Dec 25, 2014, Accepted date: Mar 05, 2015, Published date: Mar 12, 2015

Copyright: (c) 2015 Nadia Mohamed Taha. This is an open-access article distributed under the terms of the Creative Commons Attribution License, which permits unrestricted use, distribution, and reproduction in any medium, provided the original author and source are credited.

\section{Introduction}

End-stage renal disease (ESRD) is associated with an increased prevalence of sleep disturbances, which have a major influence on vitality and general health of hemodialysis patients [1]. On average, $50-80 \%$ of these patients suffer from delayed sleep onset and have trouble staying asleep [2,3]. A recent study carried out at Zagazig and Ain-Shams University Hospitals in Egypt revealed that more than half (56.7\%) of patients undergoing hemodialysis had sleep disturbances [4]. Sleep disorders such as restless legs, periodic limb movements, sleep apnea, and sleep complaints such as insomnia and day time sleepiness are very common despite treatment with hemodialysis [5]. Such disorders affect the quality of life (QOL) with serious socioeconomic implications [6,7], and they may increase cardiovascular morbidity and mortality [8], with a higher risk of allcause mortality [9].

Sleep disorders have emerged as an important health hazard and some of the factors involved in the pathogenesis of renal disease are the same that cause or are associated with sleep apnea [10]. The factors contributing to sleep disturbances in patients on dialysis have been classified as treatment-related (e.g. premature discontinuation of dialysis, rapid changes in fluid and electrolyte and acid base balance, alteration in medications, dialysis shift); psychological (e.g. anxiety, depression, stress, and worry); disease-related (e.g. co-morbid conditions, anaemia, uraemia and metabolic changes); lifestyle-related (e.g. excess coffee, smoking, poor sleep hygiene); and demographic factors (e.g. older age, gender, race) $[1,11]$. Nonetheless, the increase in the prevalence of sleep disorders in ESRD patients has been attributed to potential patient selection bias and comorbid conditions such as cardiovascular disease, diabetes mellitus, obesity and older age [12].

Healthcare has traditionally focused on diagnosing and treating physical signs and symptoms. However, it is now recognized that the physical, psychological and social aspects of a patient's life are important issues to consider when caring for people with chronic illnesses such as ESRD with sleep disturbances. Nurses play an important role in this aspect through providing optimal dialysis, a supportive environment and comprehensive and continuous education, ensuring holistic care $[13,14]$. However, studies about the role of nurses' intervention on sleep abnormalities in patients on hemodialysis taking various influencing factors into account are still under the study.

\section{Aim of the Study}

The aim of this study was assess the effectiveness of nursing intervention guidelines in improving sleep pattern and quality in ESRD patients undergoing hemodialysis in morning and afternoon shift. The research hypothesis was that the nursing intervention guidelines based on identified factors underlying the sleep disorders among ESRD patients undergoing hemodialysis will improve their sleep pattern and quality in morning shift and afternoon shift.

\section{Subjects and Methods}

\section{Research Design and Setting}

A controlled quasi-experimental design with pre-post-follow-up assessment was used in this study. Participating patients were assessed at three time intervals: before, at completion, and 12 weeks after completion of the health guidance nursing intervention. The study was conducted at the Nephrology Hemodialysis Units at the Zagazig University Hospital.

\section{Participants}

The study population consisted of all patients undergoing chronic hemodialysis in the study setting. The inclusion criteria were age 18-75 years, having hemodialysis sessions at the same hour of the day, either in the morning (6:30 to $10: 30 \mathrm{AM})$ or afternoon (3:30 to 7:30 PM) sessions, for at least three months. The exclusion criteria were having cancer, severe neurological, hepatic, lung or cardiac diseases, or recent infections. The sample size was calculated to a difference of at least 1 hour night sleep between the morning and afternoon sessions' patients with a standard deviation 1 hour at $95 \%$ level of confidence and $90 \%$ power. This required 23 patients per group, which was increased to 30 patients per group to account for dropouts. Patients were consecutively recruited from the study population according to eligibility criteria to either the morning or afternoon groups.

\section{Data Collection Tools}

The researchers developed an interview questionnaire to collect data regarding patient's socio-demographic characteristics, physical health problems, psychosocial factors and feeling, in addition to Pittsburgh Sleep Quality Index (PSQI) and the Epworth Sleepiness Scale (ESS). The patient's blood pressure and height and weight were recorded, and the Body Mass Index (BMI) calculated, measurements of serum creatinine, hemoglobin, calcium, hematocrit, urea and 
Page 2 of 9

phosphates as a biochemical factors. The biochemical data were collected from patients' files.

In the physical health problems section, the patient was asked about the presence of symptoms related to various body systems such as cough, apnea, and shortness of breath in the respiratory system, and cramps and joint pains in the musculoskeletal system. Each symptom reported to be present was scored 1 , and the total sum was counted as the total number of symptoms.

The patient's perception of the psychosocial factors was assessed using a 4-point Likert scale type measuring the social factors such as "sleeping alone in room" and "troubled by others during sleep", breathing while sleeping such as "snoring" and "having problem sleeping on the back", psychosomatic state such as "anxiety" and "fatigue", and patient feelings such as "feeling scared" and "feeling fatigue with no energy." The scale from "never" to "always" was scored 1 to 4 so that a higher score indicates more trouble with the psychosocial factors. The scores of the items were summed-up and the total divided by the number of the items, giving a mean score; means and standard deviations and medians were computed $[1,4,11,15]$.

Sleep quality was assessed using the PSQI. This scale has seven components namely subjective quality of sleep; sleep onset latency; sleep duration; sleep efficiency; presence of sleep disturbances; use of hypnotic-sedative medication; and presence of daytime disturbances, as an indication of daytime alertness [16]. Individuals with total PSQI score of six or more are considered poor sleepers [17]. In addition, the patient was asked to subjectively judge whether the sleep hours were sufficient or not.

Daytime sleepiness was assessed by the Epworth Sleepiness Scale (ESS) [18]. This is a validated 8-item questionnaire inquiring about respondent's expectation of dozing in eight hypothetical situations such as sitting and reading, watching TV, sitting inactive in a public place, as a passenger in a car for 1 hour without a break, lying down in the afternoon when circumstances permit, sitting and talking to someone, sitting quietly after lunch, and in a car while stopped for a few minutes in traffic. Dozing probability ratings range from zero (no probability) to three (high probability). A total score of 10 or more indicates excessive daytime somnolence [6].

\section{Study Manoeuvre}

The study was achieved through preparatory, assessment, planning, implementation, and evaluation phases.

\section{Preparatory Phase and Pilot Study}

The researchers prepared the data collection tools and the health guidance educational nursing intervention based on pertinent literature. The interview questionnaire was face and content-validated by five experts from medical-surgical nursing and two from the nephrology department in the Faculty of Medicine. A pilot study was conducted in June 2012 on six ESRD patients from the study setting to assess the practicability of the tools and the reliability of their scales. Based on the findings of the pilot study, the necessary modifications were done. The pilot sample was included in the nursing intervention but not in data analyses. The reliability of the ESS and psychosocial scales turned to be high with Cronbach's alpha coefficients 0.80 and 0.96 respectively.

\section{Assessment}

Upon getting their informed consents, eligible participants were alternatively assigned to either the morning or afternoon groups, ending with 30 patients in each group. The morning group patients received the structured nursing intervention during and after hemodialysis in the morning, whereas the afternoon group received the same intervention before and during hemodialysis in the afternoon. The socio-demographic and clinical data were obtained by the researchers through interviewing using the developed questionnaire. The biochemical data were collected from patients' files; they included measurements of serum creatinine, hemoglobin, calcium, hematocrit, urea and phosphates. All variables were measured concurrently. The baseline data collection lasted from June to the end of July 2012. This was done three days per week from 8.30 AM to 10.30 AM for morning group and from 3.00 PM to 5.00 PM for afternoon group. Each interview took from 30 to 40 minutes.

\section{Planning}

Based on assessment data and related literature, the researchers prepared an educational intervention guidelines to help improving patients' sleep, with a booklet in Arabic language to be administered by the end of the sessions. This non-pharmacological nursing intervention included daytime physical activity with attempts to keep subjects out of bed, with afternoon bright light exposure, a consistent bedtime routine, night time care routines to minimize sleep apnea and disruption, in addition to strategies to reduce night time noise. The most common behavioral treatments used were sleep hygiene, sleep restriction, stimulus control, and relaxation training which are combined for optimal success [19].

- Sleep hygiene is used to improve sleep onset and maintain continuous sleep; it is most effective when combined with other behavioral therapies. The patient is advised to do avoid caffeinated beverages and nicotine for at least six hours before bedtime, avoid alcohol, exercise regularly but not for at least three hours prior to bedtime, avoid naps if having trouble falling asleep at night, establish a regular routine for bedtime and morning awakening, even on weekends, use the bed only for sleep or sex, but avoid reading or watching television, get out of bed and engage in some relaxing activity if one cannot fall asleep after lying in bed for 30 minutes and return to bed only when one feels sleepy, eliminate clocks in the bedroom, eat meals regularly and do not go to bed hungry or full stomach, and try not to take one's problems to bed.

- Sleep restriction is a temporary treatment based on the notion that sleep deprivation leads to consolidation of sleep. To increase sleep efficiency to about $90 \%$ the patient is instructed to restrict time in bed to achieve some degree of sleep deprivation, not spend more than 15 minutes awake either at the beginning of sleep or after getting up, avoid activities at bedtime, get out of bed at predetermined time no matter how little sleep was, and use medications as prescribed.

- Stimulus control therapy is based on the assumption that the patient views the bedroom as a place where sleep cannot be obtained. Hence, the patient is instructed to change behavior so that the bedroom and bed is associated strictly with sleep. The patient is to get out of bed if he/she cannot fall asleep after 10-15 minutes. However, the clock should not be watched as this behavior may condition sleeplessness. Once up, the patient is to go to another room and engage in activity that is relaxing. When sleepy, he/she should return to bed. 
- Relaxation training may be helpful in patients who are apneic, anxious, or tend to bring their problems to bed. It uses biofeedback techniques or other maneuvers to reduce musculoskeletal tension, best performed before sleep. They include calm breathing, relaxation exercises, and relaxation training with listening to music.

\section{Implementation}

The application of the guidelines by the researchers lasted for 6 months from the beginning of August to the end of January 2013. The researchers pre-determined appointments with the patients through phone calls. The session took approximately between 30 to 40 minutes to complete it. The nursing intervention guideline was designed as booklet, poster, data show and CD films. It was administered through individual sessions. The total number of sessions was nine: three theoretical and six practical. The theoretical sessions covered 1) knowledge about hemodialysis, and its effect on the body system; 2) definition of sleep disorders, factors affecting on sleep pattern for hemodialysis patients (physical, psychological, social and spiritual); 3 ) behavioral management for sleep disorders (sleep hygiene, sleep restriction, stimulus control and physical problem). As for the practical sessions, the first two covered physical support through nursing intervention for health problems reported by the patient, the 3rd to 5th involved the physiological coping strategies through relaxation training, deep breathing technique, meditation, and exercises, and the 6th session covered psychosocial support.

At the beginning of the first session, an orientation to the intervention guideline and its purpose was presented. Each session started by a summary about what had been given through the previous session and the objectives of the new one, taking into consideration the use of simple language to suit the educational level of the patient. Discussions, motivation and reinforcement were used to enhance learning. Direct reinforcement in the form of a copy of health guideline for nursing intervention was offered for each patient to use it as future reference.

\section{Evaluation}

The effect of the nursing intervention on sleep pattern disorders was assessed immediately post-intervention and after 3 months using the same data collection tools of the pre-intervention assessment.

\section{Ethical Considerations}

The study protocol was approved by the local Research Ethics Committee. Necessary approvals from the settings' administration were obtained in order to carry out the study. The researchers briefed participants with the purpose and nature of the study and the educational nursing intervention, and their informed consents were secured. They were reassured about confidentiality and about their rights to refuse or withdraw at any time. The study maneuvers could not have any foreseen harmful effects on participants.

\section{Statistical Analysis}

Data entry and statistical analysis were done using SPSS 18.0 statistical software package. Cronbach alpha coefficient was calculated to assess the reliability of the developed tools through their internal consistency. Quantitative continuous data were compared using the non-parametric Mann-Whitney or Kruskal-Wallis tests. Categorical variables were compared using chi-square test. Whenever the expected values in one or more of the cells in a $2 \times 2$ tables was less than 5 , Fisher exact test was used instead. In larger than $2 \times 2$ cross-tables, no test could be applied whenever the expected value in $10 \%$ or more of the cells was less than 5 . In order to identify the independent predictors of the number of sleep hours and the sleep quality score, multiple linear regression analysis was used after testing for normality, and homoscedasticity, and analysis of variance for the full regression models were done. Statistical significance was considered at $\mathrm{p}$-value $<0.05$.

\section{Results}

The patients in the morning and afternoon groups had similar socio-demographic characteristics as indicated in Table 1. They were mostly males, married, with no formal education, employed, living with the family, and with close median ages of 54.5 and 57.0 years respectively. Slightly more than half of both groups had rural residence, $56.7 \%$ and $60.0 \%$ respectively, and sufficient income, $56.7 \%$ for both groups. The median duration of illness was slightly longer in the morning group (3 years) compared with the afternoon group (2 years), but the difference was not statistically significant $(\mathrm{p}=0.09)$. The majority of the patients in both groups were overweight or obese, $76.7 \%$ and $83.3 \%$, respectively.

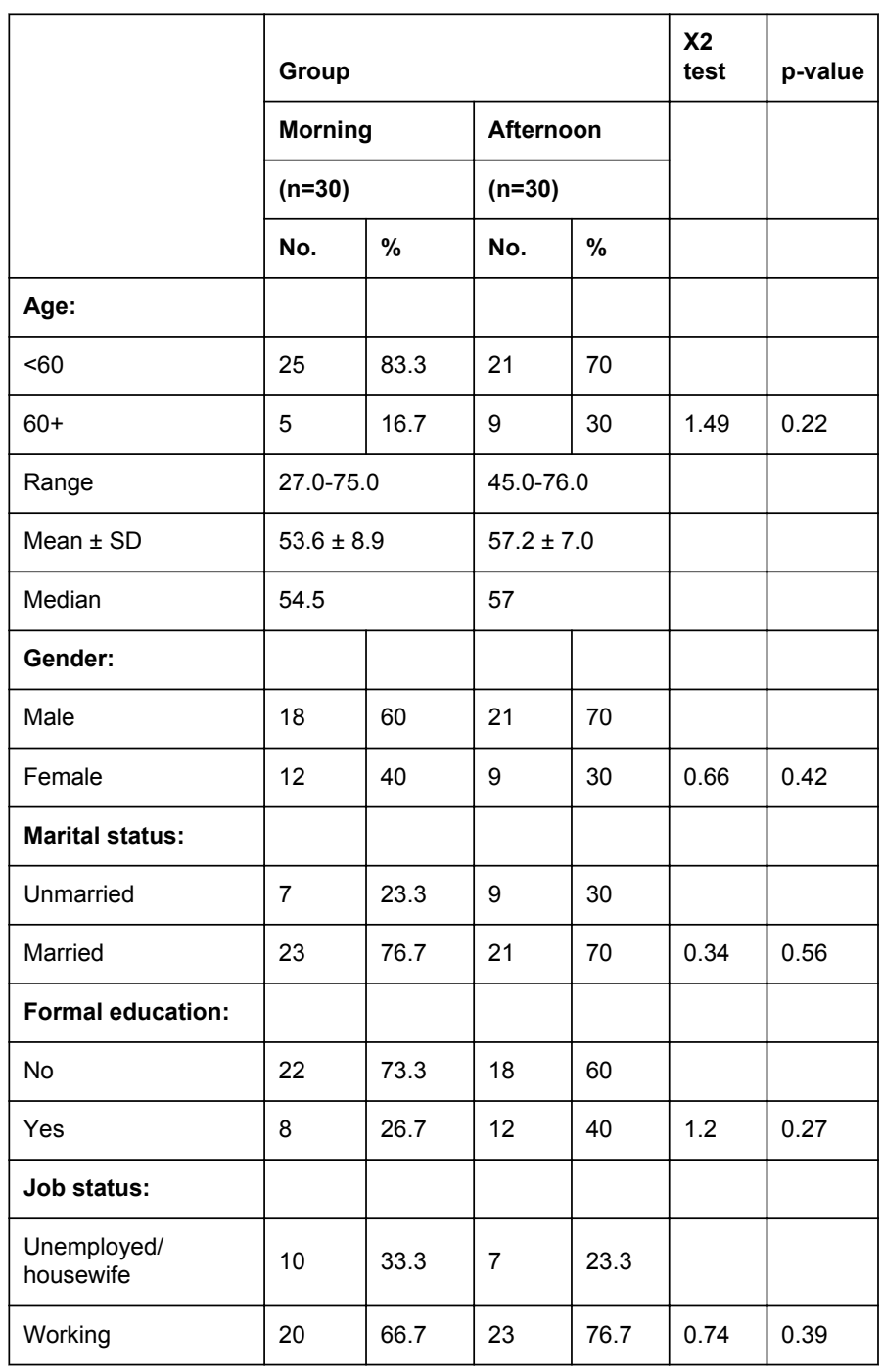


Citation: Taha NM (2015) Can A Nursing Intervention Improve the Sleep Pattern Disorders in Patients Undergoing Hemodialysis in Morning and Afternoon Shifts?. J Nurs Care 4: 235. doi:10.4172/2167-1168.1000235

Page 4 of 9

\begin{tabular}{|l|l|l|l|l|l|l|}
\hline Live with: & & & & & & \\
\hline Family & 25 & 83.3 & 21 & 70 & & \\
\hline Alone & 5 & 16.7 & 9 & 30 & 1.49 & 0.22 \\
\hline Residence: & & & & & & \\
\hline Rural & 17 & 56.7 & 18 & 60 & & \\
\hline Urban & 13 & 43.3 & 12 & 40 & 0.07 & 0.79 \\
\hline Income: & & & & & & \\
\hline Sufficient & 17 & 56.7 & 17 & 56.7 & & \\
\hline Insufficient & 13 & 43.3 & 13 & 43.3 & 0 & 1 \\
\hline $\begin{array}{l}\text { Duration of illness } \\
\text { (years): }\end{array}$ & & & & & & \\
\hline$<3$ & 10 & 33.3 & 16 & 53.3 & & \\
\hline $3+$ & 20 & 66.7 & 14 & 46.7 & & \\
\hline Range & $1.0-20.0$ & $3.7 \pm 3.6$ & 3 & $2.5 \pm 1.8$ & 2.94 & 0.09 \\
\hline Mean \pm SD & 3 & 23.3 & 5 & 16.7 & & \\
\hline Median & 23 & 76.7 & 25 & 83.3 & 0.42 & 0.52 \\
\hline Obesity (BMI): & & & 2 & & & \\
\hline Normal & & & & & & \\
\hline Overweight/obese & & & & & & \\
\hline
\end{tabular}

Table 1: Socio-demographic characteristics of patients in the morning and afternoon groups

As Table 2 illustrates, the most commonly reported problems reported by patients before the intervention in both groups were cough, apnea, tachycardia and chest pain, numbness/tingling and difficult concentration, bone/joint pains, itching, and irritability and dependence in the activities of daily living. It is noticed that patients in the morning group had significantly higher prevalence of apnea, difficult concentration, and bone/joint pain, and lower prevalence of shortness of breath, headache, fatigue, and cramps. Their median of total number of reported problems was lower compared with the afternoon group, 15 versus 16 problems respectively, $\mathrm{p}=0.006$.

\begin{tabular}{|c|c|c|c|c|c|c|}
\hline \multirow{4}{*}{ Problems } & \multicolumn{4}{|c|}{ Group } & \multirow[t]{3}{*}{$\mathrm{X} 2$ test } & \multirow[t]{3}{*}{$p$-value } \\
\hline & \multicolumn{2}{|c|}{ Morning } & \multicolumn{2}{|c|}{ Afternoon } & & \\
\hline & \multicolumn{2}{|c|}{$(n=30)$} & \multicolumn{2}{|c|}{$(n=30)$} & & \\
\hline & No. & $\%$ & No. & $\%$ & & \\
\hline \multicolumn{7}{|l|}{ Respiratory: } \\
\hline Cough & 27 & 90 & 28 & 93.3 & Fisher & 1 \\
\hline Apnea & 26 & 86.7 & 19 & 63.3 & 4.36 & $0.04^{*}$ \\
\hline Shortness of breath & 6 & 20 & 19 & 63.3 & 11.59 & $0.001^{*}$ \\
\hline \multicolumn{7}{|l|}{ Circulatory: } \\
\hline Tachycardia & 29 & 96.7 & 29 & 96.7 & Fisher & 1 \\
\hline
\end{tabular}

\begin{tabular}{|c|c|c|c|c|c|c|}
\hline Chest pain & 24 & 80 & 26 & 86.7 & 0.48 & 0.49 \\
\hline \multicolumn{7}{|l|}{ GIT: } \\
\hline Dry mouth & 3 & 10 & 9 & 30 & 3.75 & 0.053 \\
\hline Diarrhea & 0 & 0 & 0 & 0 & 0 & 1 \\
\hline \multicolumn{7}{|l|}{ Neurological: } \\
\hline Numbness/tingling & 29 & 96.7 & 26 & 86.7 & Fisher & 0.35 \\
\hline Trouble sleep & 7 & 23.3 & 10 & 33.3 & 0.74 & 0.39 \\
\hline Headache & 3 & 10 & 17 & 56.7 & 14.7 & $<0.001^{*}$ \\
\hline $\begin{array}{l}\text { Difficult } \\
\text { concentration }\end{array}$ & 28 & 93.3 & 19 & 63.3 & 7.95 & $0.005^{\star}$ \\
\hline Fatigue & 4 & 13.3 & 17 & 56.7 & 12.38 & $<0.001^{*}$ \\
\hline \multicolumn{7}{|l|}{ Musculoskeletal: } \\
\hline Cramps & 1 & 3.3 & 12 & 40 & 11.88 & $0.001^{*}$ \\
\hline Bone/joint pain & 30 & 100 & 24 & 80 & Fisher & $0.02^{*}$ \\
\hline \multicolumn{7}{|l|}{ Integumentary: } \\
\hline Itching & 30 & 100 & 28 & 93.3 & Fisher & 0.49 \\
\hline \multicolumn{7}{|l|}{ Psychological: } \\
\hline Worry & 2 & 6.7 & 6 & 20 & Fisher & 0.25 \\
\hline Irritability & 29 & 96.7 & 28 & 93.3 & Fisher & 1 \\
\hline Nervousness & 21 & 70 & 18 & 60 & 0.66 & 0.42 \\
\hline Dependence in ADL & 15 & 50 & 18 & 60 & 0.61 & 0.44 \\
\hline \multicolumn{7}{|l|}{$\begin{array}{l}\text { Total physical } \\
\text { problems: }\end{array}$} \\
\hline Range & \multicolumn{2}{|c|}{ 17-Nov } & \multicolumn{2}{|c|}{ 19-Nov } & & \\
\hline Mean \pm SD & \multicolumn{2}{|c|}{$14.2 \pm 2.0$} & \multicolumn{2}{|c|}{$16.1 \pm 2.5$} & $U=7.55$ & $0.006^{*}$ \\
\hline Median & \multicolumn{2}{|l|}{15} & \multicolumn{2}{|l|}{16} & & \\
\hline
\end{tabular}

Table 2: Problems reported by patients in the morning and afternoon groups before the intervention $\left.{ }^{*}\right)$ Statistically significant at $\mathrm{p}<0.05$, (--) Test result not valid, (U) Mann Whitney test, (ADL) Activities of Daily Living

Table 3 illustrates similar sleep patterns among patients in the morning and afternoon groups before the intervention, with all patients having poor quality sleep, with a median of 4 hours night sleep in both groups, and no statistically significant differences. As regards the factors affecting sleep, it is noticed that the mean scores of social and patient feelings factors were statistically significantly higher among patients in the morning group, whereas those in the afternoon group had higher mean score of breathing while sleeping. Nonetheless, the differences in the medians were trivial, and no statistically significant difference was revealed between the two groups in the total factors score.

\begin{tabular}{|l|l|l|l|l|}
\hline & \multicolumn{2}{|l|}{ Group } & Mann & p-value \\
\cline { 2 - 5 } & Morning & Afternoon & Whitney & \\
\hline
\end{tabular}


Citation: Taha NM (2015) Can A Nursing Intervention Improve the Sleep Pattern Disorders in Patients Undergoing Hemodialysis in Morning and Afternoon Shifts?. J Nurs Care 4: 235. doi:10.4172/2167-1168.1000235

Page 5 of 9

\begin{tabular}{|c|c|c|c|c|c|c|}
\hline & \multicolumn{2}{|c|}{$(n=30)$} & \multicolumn{2}{|c|}{$(n=30)$} & \multirow[t]{2}{*}{ test } & \\
\hline & No & $\%$ & No. & $\%$ & & \\
\hline \multicolumn{7}{|l|}{ Sleep hours: } \\
\hline Range & \multicolumn{2}{|c|}{$2.0-5.0$} & \multicolumn{2}{|c|}{$2.0-5.0$} & & \\
\hline Mean \pm SD & \multicolumn{2}{|c|}{$3.7 \pm 0.6$} & \multicolumn{2}{|c|}{$3.6 \pm 0.6$} & $\mathrm{U}=0.95$ & 0.33 \\
\hline Median & \multicolumn{2}{|c|}{4} & \multicolumn{2}{|l|}{4} & & \\
\hline $\begin{array}{l}\text { Sleep } \\
\text { sufficient: }\end{array}$ & 0 & 0 & 0 & 0 & -- & -- \\
\hline \multicolumn{7}{|l|}{$\begin{array}{l}\text { Daytime } \\
\text { sleepiness score } \\
\text { (ESS): }\end{array}$} \\
\hline Range & \multicolumn{2}{|c|}{$0.0-1.0$} & \multicolumn{2}{|c|}{$0.0-2.0$} & & \\
\hline Mean \pm SD & \multicolumn{2}{|c|}{$0.0 \pm 0.2$} & \multicolumn{2}{|c|}{$0.1 \pm 0.4$} & 0 & 0.98 \\
\hline Median & \multicolumn{2}{|l|}{0} & \multicolumn{2}{|l|}{0} & & \\
\hline \multicolumn{7}{|l|}{$\begin{array}{l}\text { Sleep quality } \\
\text { score (PSQI): }\end{array}$} \\
\hline Poor & 30 & 100 & 30 & 100 & & \\
\hline Fair & 0 & 0 & 0 & 0 & & \\
\hline Range & \multicolumn{2}{|c|}{$7.0-7.0$} & \multicolumn{2}{|c|}{$6.0-7.0$} & & \\
\hline Mean \pm SD & \multicolumn{2}{|c|}{$7.0 \pm 0.0$} & \multicolumn{2}{|c|}{$7.0 \pm 0.2$} & 1 & 0.32 \\
\hline Median & \multicolumn{2}{|l|}{7} & \multicolumn{2}{|l|}{7} & & \\
\hline $\begin{array}{l}\text { Regular sleep } \\
\text { during session }\end{array}$ & 0 & 0 & 0 & 0 & 0 & 1 \\
\hline \multicolumn{7}{|l|}{$\begin{array}{l}\text { Total abnormal } \\
\text { physical signs }\end{array}$} \\
\hline Range & \multicolumn{2}{|c|}{$11.0-17.0$} & \multicolumn{2}{|c|}{$11.0-21.0$} & $\mathrm{U}=7.55$ & $0.006^{*}$ \\
\hline Mean \pm SD & \multicolumn{2}{|c|}{$14.2 \pm 2.0$} & \multicolumn{2}{|c|}{$16.1 \pm 2.5$} & & \\
\hline Median & \multicolumn{2}{|c|}{15} & \multicolumn{2}{|l|}{16} & & \\
\hline \multicolumn{7}{|l|}{$\begin{array}{l}\text { Social factors } \\
(\max =4):\end{array}$} \\
\hline Range & \multicolumn{2}{|c|}{$2.7-2.7$} & $2.0-$ & & & \\
\hline Mean \pm SD & & & 2.5 & & 9.022 & $0.003^{*}$ \\
\hline
\end{tabular}

\begin{tabular}{|c|c|c|c|c|}
\hline Median & 2.7 & 2.7 & & \\
\hline \multicolumn{5}{|c|}{$\begin{array}{l}\text { Breathing while } \\
\text { sleeping } \\
\text { (max=4): }\end{array}$} \\
\hline Range & $3.8-3.8$ & $3.6-4.0$ & & \\
\hline Mean \pm SD & $3.8 \pm 0.0$ & $3.9 \pm 0.1$ & 21.992 & $<0.001^{*}$ \\
\hline Median & 3.8 & 3.95 & & \\
\hline \multicolumn{5}{|c|}{$\begin{array}{l}\text { Psychosomatic } \\
\text { state }(\max =4) \text { : }\end{array}$} \\
\hline Range & $4.0-4.0$ & $4.0-4.0$ & & \\
\hline Mean \pm SD & $4.0 \pm 0.0$ & $4.0 \pm 0.0$ & -- & -- \\
\hline Median & 4 & 4 & & \\
\hline \multicolumn{5}{|c|}{$\begin{array}{l}\text { Patient feelings } \\
(\max =4):\end{array}$} \\
\hline Range & $4.0-4.0$ & $3.8-4.0$ & & \\
\hline Mean \pm SD & $4.0 \pm 0.0$ & $3.9 \pm 0.1$ & 10.412 & $0.001^{*}$ \\
\hline Median & 4 & 4 & & \\
\hline \multicolumn{5}{|c|}{$\begin{array}{l}\text { Total factors } \\
(\max =4):\end{array}$} \\
\hline Range & 3.6-3.6 & $3.4-3.7$ & & \\
\hline Mean \pm SD & $3.6 \pm 0.0$ & $3.6 \pm 0.1$ & 0.158 & 0.691 \\
\hline Median & 3.6 & 3.6 & & \\
\hline
\end{tabular}

Table 3: Pre-intervention sleep patterns and related factors among patients in the morning and afternoon groups, $\left(^{*}\right)$ Statistically significant at $\mathrm{p}<0.05,(--)$ Test result not valid

Concerning the effects of the intervention, Table 4 demonstrates statistically significant improvements in all sleep parameters and the associated physical problems and psychosocial factors in both the morning and afternoon groups. The only exception was regarding the sleep hours, which did not demonstrate statistically significant changes in the afternoon group. Meanwhile, the median sleep hours in the morning group rose from 4 to 6 hours throughout the intervention $(\mathrm{p}<0.001)$.

\begin{tabular}{|c|c|c|c|c|c|c|c|c|}
\hline & \multicolumn{2}{|l|}{ Pre } & \multicolumn{2}{|l|}{ Post } & \multicolumn{2}{|l|}{ FU } & \multirow{2}{*}{$\begin{array}{l}\text { Kruskal Wallis } \\
\text { Test }\end{array}$} & \multirow[t]{2}{*}{ p-value } \\
\hline & Mean \pm SD & Median & Mean \pm SD & Median & Mean \pm SD & Median & & \\
\hline \multicolumn{9}{|l|}{ Morning: } \\
\hline Sleep hrs & $3.7 \pm 0.6$ & 4 & $5.4 \pm 0.9$ & 6 & $6.2 \pm 0.8$ & 6 & 60.73 & $<0.001^{*}$ \\
\hline Sleepiness score (ESS) & $0.0 \pm 0.2$ & 0 & $3.1 \pm 2.4$ & 3 & $4.5 \pm 2.7$ & 4 & 51.73 & $<0.001^{*}$ \\
\hline Sleep quality (PSQI) & $7.0 \pm 0.0$ & 7 & $2.6 \pm 0.9$ & 2 & $2.5 \pm 1.2$ & 2 & 65.68 & $<0.001^{*}$ \\
\hline Total physical problems & $14.2 \pm 2.0$ & 15 & $6.2 \pm 3.6$ & 6 & $2.7 \pm 2.2$ & 2 & 66.64 & $<0.001^{*}$ \\
\hline
\end{tabular}


Citation: Taha NM (2015) Can A Nursing Intervention Improve the Sleep Pattern Disorders in Patients Undergoing Hemodialysis in Morning and Afternoon Shifts?. J Nurs Care 4: 235. doi:10.4172/2167-1168.1000235

Page 6 of 9

\begin{tabular}{|l|l|l|l|l|l|l|l|l|}
\hline Total spiritual feeling & $4.0 \pm 0.0$ & 4 & $3.3 \pm 0.0$ & 3 & $3.3 \pm 0.0$ & 3 & 62.87 & $<0.001^{*}$ \\
\hline Total psychosocial factors & $3.6 \pm 0.0$ & 3.6 & $1.3 \pm 0.2$ & 1.3 & $1.3 \pm 0.2$ & 1.2 & 64.88 & $<0.001^{*}$ \\
\hline Afternoon: & & & & & & & & \\
\hline Sleep hrs & $3.6 \pm 0.6$ & 4 & $3.6 \pm 0.6$ & 4 & $3.6 \pm 0.6$ & 4 & 0 & 1 \\
\hline Sleepiness score (ESS) & $0.1 \pm 0.4$ & 0 & $7.7 \pm 3.6$ & 8 & $9.5 \pm 4.2$ & 12 & 56.09 & $<0.001^{*}$ \\
\hline Sleep quality (PSQI) & $7.0 \pm 0.2$ & 7 & $1.9 \pm 0.3$ & 2 & $1.9 \pm 0.3$ & 2 & 81.78 & $<0.001^{*}$ \\
\hline Total physical problems & $16.1 \pm 2.5$ & 16 & $7.9 \pm 2.8$ & 8 & $4.8 \pm 3.5$ & 3.5 & 64.49 & $<0.001^{*}$ \\
\hline Total spiritual feeling & $3.9 \pm 0.1$ & 4 & $3.3 \pm 0.0$ & 3 & $3.2 \pm 0.0$ & 3 & 62.45 & $<0.001^{*}$ \\
\hline Total psychosocial factors & $3.6 \pm 0.1$ & 3.6 & $1.2 \pm 0.1$ & 1.2 & $1.2 \pm 0.1$ & 1.2 & 78.62 & $<0.001^{*}$ \\
\hline
\end{tabular}

Table 4: Scores of sleep pattern and quality and perception of factors affecting sleep among patients in the morning and afternoon groups throughout the intervention, $\left({ }^{*}\right)$ Statistically significant at $\mathrm{p}<0.05$

As for the laboratory results, Figures 1 to 3 demonstrate statistically significant trends of improvement of the levels of hemoglobin, serum calcium, and blood urea in both groups throughout the intervention. It is noticed that the levels of hemoglobin and calcium were higher in the afternoon group while the level of urea was lower among them, with statistically significant differences.

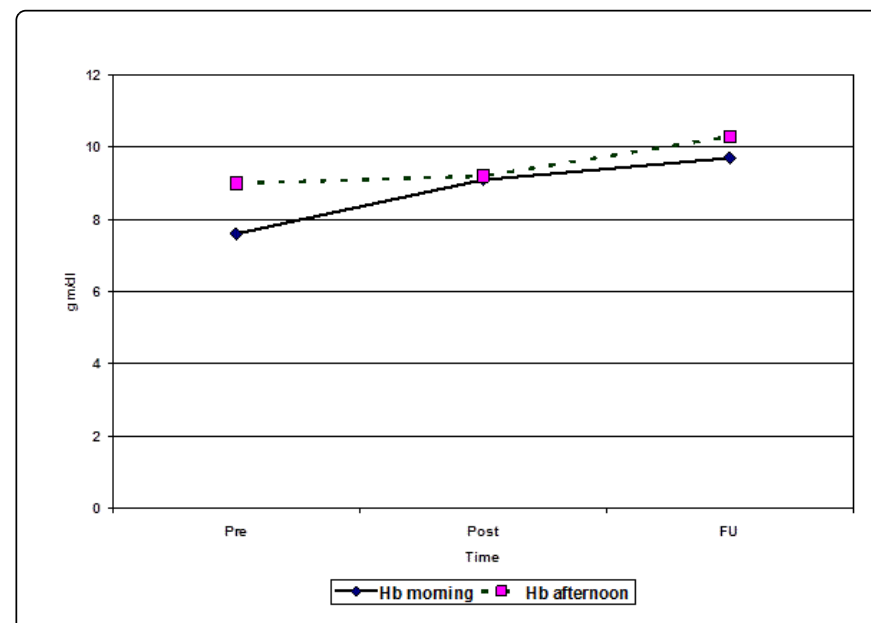

Figure 1: Statistically significant at $\mathrm{p}<0.05: 1)$ Time trend in both groups 2) Between groups at FU, Laboratory $\mathrm{Hb}$ results of patients in the study and control groups throughout the intervention

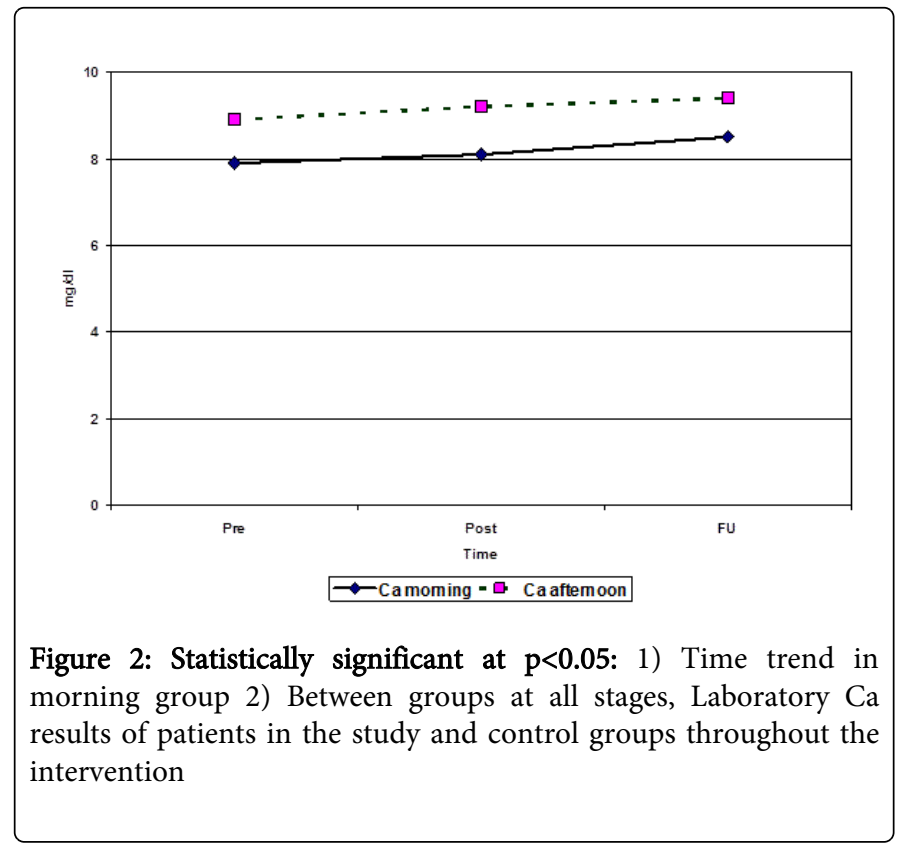


Page 7 of 9

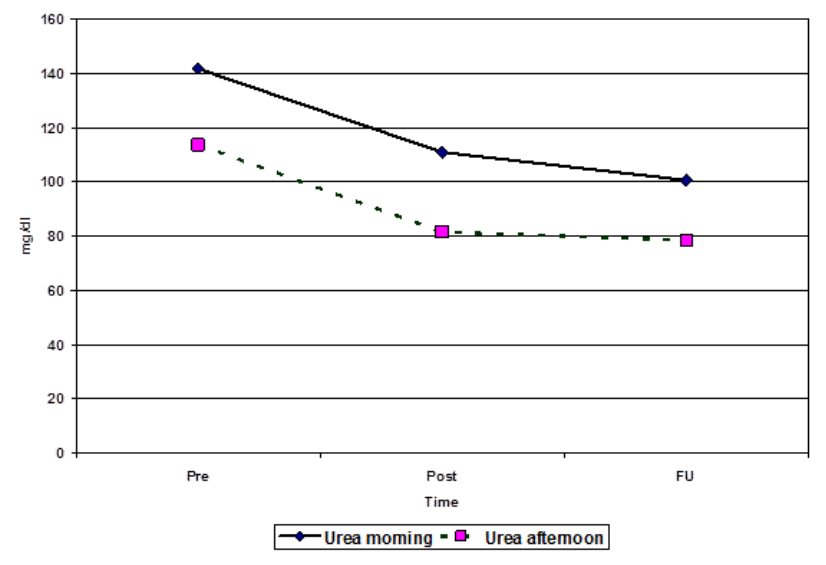

Figure 3: Statistically significant at $\mathrm{p}<0.05: 1)$ Time trend in both groups 2) Between groups at all post and FU, Laboratory Blood Urea results of patients in the study and control groups throughout the intervention

Table 5 displays the best fitting multiple linear regression models for the number of sleep hours and its quality throughout the study phases. It shows that being in the afternoon group, having more reported problems, and having a higher score of patient feelings factor were the statistically significant independent negative predictors of the number of sleep hours. The model r-square indicates that these factors explain $56 \%$ of the improvement in the number of sleep hours. Meanwhile, other variables such as blood pressure, BMI, hemoglobin and urea, as well as the scores of factors had no significant influence on the sleep hours.

\begin{tabular}{|c|c|c|c|c|c|c|c|}
\hline & \multicolumn{2}{|c|}{ Unstandardized } & \multirow{2}{*}{$\begin{array}{l}\text { Standardized } \\
\text { Coefficients }\end{array}$} & \multirow{2}{*}{ t-test } & \multirow{3}{*}{$\begin{array}{l}\mathrm{p}- \\
\text { value }\end{array}$} & \multirow{2}{*}{\multicolumn{2}{|c|}{$\begin{array}{l}95 \% \\
\text { Confidence } \\
\text { Interval for B }\end{array}$}} \\
\hline & \multicolumn{2}{|c|}{ Coefficients } & & & & & \\
\hline & B & $\begin{array}{l}\text { Std. } \\
\text { Error }\end{array}$ & & $\begin{array}{l}\text { Low } \\
\text { er }\end{array}$ & & Upper & \\
\hline \multicolumn{8}{|l|}{ Sleep hours } \\
\hline Constant & 7.56 & 0.27 & & $\begin{array}{l}28.0 \\
8\end{array}$ & $\begin{array}{l}<0.00 \\
1\end{array}$ & 7.03 & 8.09 \\
\hline Group & \multirow[b]{2}{*}{-1.29} & \multirow[b]{2}{*}{0.14} & \multirow[b]{2}{*}{-0.52} & \multirow[b]{2}{*}{-9.46} & \multirow{2}{*}{$\begin{array}{l}<0.00 \\
1\end{array}$} & \multirow[b]{2}{*}{-1.56} & \multirow[b]{2}{*}{-1.02} \\
\hline $\begin{array}{l}\text { (reference: } \\
\text { morning) }\end{array}$ & & & & & & & \\
\hline $\begin{array}{l}\text { No. } \\
\text { abnormal } \\
\text { signs }\end{array}$ & -0.08 & 0.02 & -0.36 & -4.06 & $\begin{array}{l}<0.00 \\
1\end{array}$ & -0.12 & -0.04 \\
\hline $\begin{array}{l}\text { Patient } \\
\text { feelings } \\
\text { score }\end{array}$ & -0.37 & 0.14 & -0.3 & -2.62 & 0.01 & -0.65 & -0.09 \\
\hline
\end{tabular}

r-square $=0.56$, Model ANOVA: $F=56.85, p<0.001$

Variables entered and excluded: scores of factors (social, psychosomatic, breathing while sleeping) blood pressure, BMI, hemoglobin, urea

PSQI score

\begin{tabular}{|l|l|l|l|l|l|l|l|}
\hline Constant & 0.82 & 0.11 & & 7.34 & $\begin{array}{l}<0.00 \\
1\end{array}$ & 0.6 & 1.04 \\
\hline $\begin{array}{l}\text { Patient } \\
\text { feelings } \\
\text { score }\end{array}$ & -0.46 & 0.08 & -0.2 & -5.84 & $\begin{array}{l}<0.00 \\
1\end{array}$ & -0.62 & -0.31 \\
\hline $\begin{array}{l}\text { Psychsomati } \\
\text { c score }\end{array}$ & 0.82 & 0.17 & 0.48 & 4.87 & $\begin{array}{l}<0.00 \\
1\end{array}$ & 0.49 & 1.15 \\
\hline $\begin{array}{l}\text { Breathing } \\
\text { while } \\
\text { sleeping } \\
\text { score }\end{array}$ & 0.7 & 0.17 & 0.39 & 4.27 & $\begin{array}{l}<0.00 \\
1\end{array}$ & 0.38 & 1.03 \\
\hline Social score & 0.76 & 0.19 & 0.3 & 4.07 & $\begin{array}{l}<0.00 \\
1\end{array}$ & 0.39 & 1.13 \\
\hline
\end{tabular}

r-square $=0.98$, Model ANOVA: $F=1826.89, p<0.001$

Variables entered and excluded: group, number of abnormal signs, blood pressure, BMI, hemoglobin, urea

Table 5: Best fitting multiple linear regression model for the change in the number of sleep hours and PSQI throughout intervention

As regards the sleep quality score, the same table shows that the all four factors' scores (feelings, psychosomatic, breathing while sleeping, and social) were the statistically significant independent predictors of this score. The patient feelings score was the only negative predictor, while all other three factors were positive predictors. The model explains $98 \%$ of the improvement in sleep quality score as indicated by the value of r-square. Meanwhile, the group, number of abnormal signs, blood pressure, BMI, and the levels of hemoglobin and urea had no significant influence on the sleep quality score.

\section{Discussion}

Sleep disorder is a common problem in end-stage renal disease (ESRD). This study was carried out to test the hypothesis that a nursing intervention guidelines based on the identified factors affecting sleep pattern will improve the sleep pattern and quality of ESRD patients undergoing hemodialysis in morning shift and afternoon shifts. The study findings lead to acceptance of the research hypothesis although the effect was more evident in the morning sessions group.

The patients in the morning and afternoon sessions in the present study were similar in their socio-demographic characteristics. This was essential since these characteristics may influence their sleep patterns and quality as pointed out by [20] who examined the role of dialysis shift on sleep disturbances in patients on maintenance hemodialysis patient characteristics according to time of dialysis are depicted in three shift groups did not differ with respect to age, gender, marital status, education, Job status, residence, duration of illness, income, $\mathrm{BMI}$, and presence of snoring.

The current study patients also had similarly high frequencies of reported health problems that may have a negative impact on their sleep such as cough, apnea, tachypnea, tingling and numbness, bone aches, and irritability. Although the afternoon group had a significantly higher frequency of these problems, the medians were very high and very close between the two groups. Most of these symptoms may be attributed to the uremic state which affects all body systems as pointed out by [21,22]. Furthermore, Taha [4] found a high prevalence of dependence in the activities of daily living among ESRD 
patients on hemodialysis, which reflected the high frequency of physical health problems among them. Moreover, the majority of the patients of the current study were overweight or obese, which may increase their risk of getting sleep apnea [23].

The morning and afternoon groups of patients in the present study also had similar baseline numbers of sleep hours, as well as the scores of sleep quality and daytime sleepiness. Their mean PSQI score (7.0) is very close to that reported by Trbojević-Stanković [24] in a study of depression and quality of sleep in maintenance hemodialysis patients where the mean PSQI was 7.8. Moreover, all of our patients had poor quality and insufficient hours before the intervention. In congruence with this, Al-Jahdali [25] mentioned that the prevalence of sleep disorders is much higher than among long-term dialysis patients compared with the general population. The similarity between the current study groups was of major importance in order to be able to assess the effect of the time of the session on the sleep pattern and quality. The lack of a difference in sleep between the morning and afternoon shift is in agreement with the finding of Bastos [26] who found that poor quality of sleep, sleep disorder and sleep abnormalities did not differ between subjects according to dialysis shifts.

The present study has also assessed the various psychosocial factors that may influence the sleep of ESRD patients undergoing dialysis. At the pre-intervention phase, patients in both groups had similarly high scores in all four groups of factors, particularly those related to their psychosomatic state, where all patients in both groups had the maximum score of 4 . This is in agreement with previous studies which reported poor physical, psychological, and social health among patients undergoing hemodialysis [27-29].

According to the present study results, the nursing intervention led to significant improvements in sleep quality and daytime sleepiness among the patients in both morning and afternoon shifts. However, the intervention was effective in increasing the sleeping hours of the morning shift patients only. This was further confirmed by multivariate analysis which identified the afternoon shift as a negative predictor of the number of sleep hours. This might be explained by the fact that the morning group may have a better chance and more time to prepare for a good night sleep compared with those in the afternoon shift who may not have an equal chance of doing this. This is particularly important given that more than half of the patients were from rural areas, which means that they may travel back home after the session, reaching homes late in the evening, and not having the opportunity to apply what they have learnt from the intervention guidelines. The finding is in agreement with Wang [30] whose study showed better sleep quality in morning dialysis shift after adjusting for other confounders.

The success of the current study intervention in improving patients' sleep quality seems to have been achieved through acting on their psychosocial related factors. This has been shown by the improvement of their scores in these factors throughout the intervention, and by the multivariate analysis which identified the independent effect of these factors on the PSQI score. In congruence with this finding regarding the effect of psychosocial factors on sleep, Lasch [31] mentioned that the physical, mental, emotional and social health may impair sleep in ESRD patients. However, other factors to be considered are the treatment-related factors, abnormalities in melatonin, alteration in thermoregulatory mechanisms, and co-morbidities [1,11].

Meanwhile, although the biochemical parameters demonstrated significant improvements in both groups throughout the intervention, none of them had an independent significant influence on patients' sleep hours or pattern. The effect of these parameters on sleep is still debatable, with some studies - agreeing with our findings - denying such relation [23,32], while other studies confirmed it $[33,34]$. Meanwhile, Khalil [35] in an Egyptian study found that and the levels of urea and creatinine might increase the incidence of sleep disorders in ESRD patients who are not maintained on hemodialysis. This issue needs further studies.

\section{Conclusion and Recommendations}

In conclusion, nursing intervention guidelines based on identified factors affecting sleep disorders can improve the sleep pattern and quality of the patients with ESRD on hemodialysis through acting on their physical, psychosocial factors and patient feelings. However, it seems to be more effective among patients having morning dialysis sessions compared with afternoon ones. Therefore, it is essential that the nurses identify the factors that may adversely affect the quality of sleep of these patients and develop strategies to reduce their sleep disorders. The findings should be further confirmed through randomized clinical trials to avoid the limitations of confounding factors. The effect of biochemical parameters on sleep quality and pattern needs further investigation.

\section{References}

1. Parker KP (2003) Sleep disturbances in dialysis patients. Sleep Med Rev 7: 131-143.

2. Perl J, Unruh ML, Chan CT (2006) Sleep disorders in end-stage renal disease: 'Markers of inadequate dialysis'? Kidney Int 70: 1687-1693.

3. Koch BCP, Nagtegaal JE, Hagen EC, Westerlaken van der MML, Boringa JBS, Kerkhof GA, Ter Wee PM.(2009) The effects of melatonin on sleepwake rhythm of daytime hemodialysis patients: a randomized placebocontrolled cross-over study (EMSCAP study) British Journal of Clinical Pharmacology; 67: 68-75

4. Taha NM, Farahat NH, and Abd Elaziz NA. (2010) Health Guidance's Effect on Patient Undergoing Hemodialysis with Health Problems, Stress and Daily Life Activities, Sc. J. Az. Med. Fac. 31: 529-554.

5. Hanly P (2009) Sleep disorders and home dialysis. Advances in chronic kidney disease. 16: 179-188.

6. Johns MW (1991) A new method for measuring daytime sleepiness: the Epworth sleepiness scale. Sleep 14: 540-545.

7. Ip MS, Lam B, Lauder IJ, Tsang KW, Chung KF, et al. (2001) A community study of sleep-disordered breathing in middle-aged Chinese men in Hong Kong. Chest 119: 62-69.

8. Masuda T, Murata M, Honma S, Iwazu Y, Sasaki N, Ogura M, Onishi A, Ando Y, Muto S, Shimada K, Kario K, Kusano E, Asano Y.(2011) Sleepdisordered breathing predicts cardiovascular events and mortality in hemodialysis patients. Nephrol Dial Transplant. 26:2289-95.

9. Kutner N, Zhang R, Johansen K, Bliwise D. Hemodial Int. (2013) Associations among nocturnal sleep, daytime intradialytic sleep, and mortality risk in patients on daytime conventional hemodialysis: US Renal Data System special study data. 17:223-9.

10. Ng YH, Meyer KB, Kusek JW, Yan G, Rocco MV, et al. (2006) Hemodialysis timing, survival, and cardiovascular outcomes in the Hemodialysis (HEMO) Study. Am J Kidney Dis 47: 614-624.

11. Merlino G, Gigli GL, Valente M (2008) Sleep disturbances in dialysis patients. J Nephrol 21 Suppl 13: S66-70.

12. Abbott KC, Reynolds JC, Trespalacios FC, Cruess D, Agodoa LY; United States Renal Data System Dialysis Morbidity and Mortality Waves III/IV (2003) Survival by time of day of hemodialysis: analysis of United States Renal Data System Dialysis Morbidity and Mortality Waves III/IV. Am J Kidney Dis 41: 796-806. 
Citation: Taha NM (2015) Can A Nursing Intervention Improve the Sleep Pattern Disorders in Patients Undergoing Hemodialysis in Morning and Afternoon Shifts?. J Nurs Care 4: 235. doi:10.4172/2167-1168.1000235

Page 9 of 9

13. Buscemi N, Vandermeer B, Hooton N, Pandya R, Tjosvold L, et al. (2006) Efficacy and safety of exogenous melatonin for secondary sleep disorders and sleep disorders accompanying sleep restriction: meta-analysis. BMJ 332: 385-393.

14. Judy A (2014) Nursing Education Loan Repayment Program (NELRP) Application and Program Guidance, U.S. Department Of Health And Human Services Health Resources And Services Administration,

15. Himmelfarb J (2005) Hemodialysis complications. Am J Kidney Dis 45: 1122-1131.

16. Harvey R. Colten and Bruce $M$ (2006) Sleep disorders and sleep deprivation: an unmet public health problem, Committee on Sleep Medicine and Research, Board on Health Sciences Policy Institute of Medicine of the National Academies of Sciences

17. Backhaus J, Junghanns K, Broocks A, Riemann D, Hohagen F (2002) Test-retest reliability and validity of the Pittsburgh Sleep Quality Index in primary insomnia. J Psychosom Res 53: 737-740.

18. Johns MW (1993) Daytime sleepiness, snoring, and obstructive sleep apnea. The Epworth Sleepiness Scale. Chest 103: 30-36.

19. Kuhlmann U, Becker HF, Birkhahn M, Peter JH, von Wichert P, et al (2000) Sleep-apnea in patients with end-stage renal disease and objective results. Clin Nephrol 53: 460-466.

20. Bastos JPC, Barroso de Sousa R, Nepomuceno LAM, GutierrezAdrianzen OA et al., (2007) Sleep Disturbances In Patients On Maintenance Hemodialysis: Role Of Dialysis Shift Medicine, department of Federal University of Ceará, Fortaleza, CE, Brasil Rev Assoc Med Bras. 53: 492-496

21. Xue JL, Ma JZ, Louis TA, Collins AJ (2001) Forecast of the number of patients with end-stage renal disease in the United States to the year 2010. J Am Soc Nephrol 12: 2753-2758.

22. CengiÄ B, ResiÄH, Spasovski G, AvdiÄ E, AlajbegoviÄA (2012) Quality of sleep in patients undergoing hemodialysis. Int Urol Nephrol 44: 557-567.

23. Abdel-Kader KH, Doharb SH, Shaha N et al. (2012) Resistant hypertension and obstructive sleep apnea in the setting of kidney disease. J Hypertens; 30: 960-966.

24. Trbojevic-Stankovic J, Stojimirovic B, Bukumiric Z, Hadzibulic E, Andric B, Djordjevic V, Marjanovic Z, Birdjozlic F, Nesic D, Jovanovic D.(2014)
Depression and quality of sleep in maintenance hemodialysis patients. Srp Arh Celok Lek.142:437-43.

25. Al-Jahdali HH, Khogeer HA, Al-Qadhi WA, Baharoon S, Tamim H, et al. (2010) Insomnia in chronic renal patients on dialysis in Saudi Arabia. J Circadian Rhythms 8: 7.

26. Bastos JP, Sousa RB, Nepomuceno LA, Gutierrez-Adrianzen OA, Bruin $\mathrm{PF}$, et al. (2007) Sleep disturbances in patients on maintenance hemodialysis: role of dialysis shift. Rev Assoc Med Bras 53: 492-496.

27. Mavanur M, Sanders M, Unruh M (2010) Sleep disordered breathing in patients with chronic kidney disease. Indian J Med Res 131: 277-284.

28. 28. Anees, M, Hameed F, Mumtaz A, Ibrahim M, Saeed M N K (2011) Dialysis-Related Factors Affecting Quality of Life in Patients on Hemodialysis, Iranian Journal of Kidney Diseases

29. Chang Y C and Yang T C, (2011) Sleep Quality and Associated Factors in Hemodialysis Patients, Acta Nephrologica 25: 97-104.

30. Wang MY, Chan SF, Chang LI, Chen TH, Tsai PS (2013) Better sleep quality in chronic haemodialyzed patients is associated with morningshift dialysis: a cross-sectional observational study. Int J Nurs Stud 50: 1468-1473.

31. Lasch KE, Abraham L, Patrick J, Piault EC, Tully SE, et al. (2011) Development of a next day functioning measure to assess the impact of sleep disturbance due to restless legs syndrome: the restless legs syndrome-next day impact questionnaire. Sleep Med 12: 754-761.

32. Ibrahim M A, Abd El Salam M H, Abdo T A, and Alloush H.( 2012) Sleep Disorders in Resistant Hypertensive Patients on Conventional Hemodialysis. Life Sci J.9:1887-1900

33. Koch BC, Nagtegaal JE, Hagen EC, van Dorp WT, Boringa JB, et al. (2008) Subjective sleep efficiency of hemodialysis patients. Clin Nephrol 70: 411-416.

34. Al-Jahdali H (2011) A comparison of sleep disturbances and sleep apnea in patients on hemodialysis and chronic peritoneal dialysis. Saudi J Kidney Dis Transpl 22: 922-930.

35. Khalil E S, Mohamed E I, Khalil G I, Sallam S M, Mohamed S S, Naga S S, and Mowafy M N (2012) Effects of sleep disordered breathing on functional capacity and quality of life in chronic kidney disease Egyptian patientsSleep and Breathing 17: 621-628 